\title{
Carcinoma de colo uterino tipo glassy cell
}

\author{
Leila C. Soares, ${ }^{1^{\star}}$ Marco A. P. Oliveira1
}

\section{Resumo}

O carcinoma de colo uterino do tipo glassy cell é uma forma rara de câncer adenoescamoso pouco diferenciado, que tipicamente afeta mulheres jovens. Seu comportamento clínico é caracterizado por curso bastante agressivo e prognóstico pobre. A principal característica anatomopatológica do câncer do tipo glassy cell é a presença de células com quantidade moderada de citoplasma com aspecto de vidro moído de aparência finamente granular. A extensão da doença, no momento do diagnóstico, é um importante fator prognóstico e o estadiamento cirúrgico é frequentemente maior do que o clínico. Relatamos o caso de uma paciente de 36 anos, branca e nulípara com queixa de sangramento vaginal irregular e dor pélvica. A paciente apresentava Papanicolaou e exame ginecológico normais, sem evidências de alterações macroscópicas em colo uterino com colposcopia insatisfatória. A ressonância nuclear magnética revelou massa em colo uterino e, devido ao seu crescimento endofítico, somente após a realização da conização foi feito o diagnóstico.

Descritores: Carcinoma adenoescamoso; Neoplasia do colo do útero; Papillomavirus humano.

\begin{abstract}
\section{Glassy cell carcinoma of the uterine cervix}

Glassy cell carcinoma of the cervix is a rare form of poorly differentiated adenosquamous cancer that typically affects younger women. Its clinical behavior is characterized by very aggressive course and poor prognosis. The main pathological feature is the presence of cells with a moderate amount of cytoplasm having a ground glass or finely granular appearance. The extent of disease at diagnosis is an important prognostic factor and surgical staging is often larger than clinical. We report a case of a 36 years-old nulliparous white female, with irregular vaginal bleeding and pelvic pain. The patient had normal Papanicolaou smear with no evidence of macroscopic changes in the cervix and the colposcopy was unsatisfactory. A magnetic resonance imaging revealed a cervix mass and, due its endophytic type of growth, only after conization the diagnosis was established.
\end{abstract}

Keywords: Adenosquamous carcinoma; Uterine cervical neoplasms; Human papillomavirus.
1. Departamento de Saúde Maternoinfantil. Serviço de Ginecologia. Universidade do Estado do Rio de Janeiro. Rio de Janeiro, RJ, Brasil.

*Endereço para correspondência:

Serviço de Ginecologia, HUPE, UERJ

Boulevard 28 de Setembro, 75, 5ㅇandar

Rio de Janeiro, RJ, Brasil. CEP: 20551-030.

E-mail: leilabrollo@gmail.com

Revista HUPE, Rio de Janeiro, 2015;14(Supl. 1):101-103

doi: 10.12957/rhupe.2015.17934

Recebido em 03/06/2015. Aprovado em 15/07/2015.

\section{Resumen}

\section{Carcinoma de tipo glassy cell del cuello uterino}

El carcinoma del cuello uterino de tipo (glacy cell) es una forma rara de cáncer adenoescamoso poco diferenciado, que por logeneral afecta a mujeres jóvenes. Su comportamiento clínico se caracteriza por un curso bastante agresivo y pronóstico pobre. La principal característica anatomopatológica del cáncer de tipo glassy cell es la presencia de células con cantidad moderada de citoplasma con aspecto de vidrio molido de apariencia finamente granular. La extensión de la enfermedad, al momento del diagnóstico, es un importante factor pronóstico y el estadiaje quirúrgico es a menudo mayor que el clínico. Presentamos el caso de una paciente de 36 años de edad, blanca y nulípara con queja de sangrado vaginal irregular y dolor pélvico. La paciente tenía prueba de Papanicolaou y examen ginecológico normal, sin evidencias de alteraciones macroscópicas en el cuello uterino con colposcopia insatisfactoria. La resonancia magnética nuclear reveló masa en el cuello uterino y, debido a su crecimiento endofítico, sólo después de que se le realizó la conización se hizo el diagnóstico. Palabras clave: Carcinoma adenoescamoso, Neoplasias del cuello uterino; Papillomavirus humano. 


\section{Caso clínico}

\section{Introdução}

O carcinoma de colo uterino tipo glassy cell é uma forma rara de câncer, responsável por apenas 1-5\% dos casos de câncer do colo do útero. Foi descrito pela primeira vez em 1956 por Cherry e Gucksmann. ${ }^{1}$ A idade média de incidência é de cerca de 10 anos menor do que a média de pacientes com carcinomas de células escamosas e de adenocarcinomas do colo do útero, ${ }^{2} \mathrm{com}$ pico de incidência entre a terceira e quarta décadas. ${ }^{3}$

Seu comportamento clínico é caracterizado pela agressividade com rápido crescimento e progressão, metástases precoces e fraca resposta à radioterapia e cirurgia. ${ }^{4} \mathrm{O}$ prognóstico no momento do diagnóstico é frequentemente sombrio. ${ }^{2}$

\section{Caso}

Mulher de 36 anos, com queixa de sangramento vaginal anormal, dor pélvica e lombar incapacitantes e perda ponderal. O exame especular não demonstrou alteração em colo uterino e exame da pelve demonstrou útero fixo, pouco aumentado de volume. Toque retal evidenciou espessamento de septo retovaginal e paramétrios espessados bilateralmente.

A ressonância nuclear magnética (RNM) evidenciou massa em colo uterino, porém a citologia não evidenciou alterações e a colposcopia foi instatisfatória. Devido à alteração encontrada na RNM, optou-se por fazer conização diagnóstica que evidenciou tumor tipo glassy cell.

Ao diagnóstico, a doença já se encontrava avançada e a paciente iniciou quadro de desidratação, disfagia, odinofagia e vômitos, não se encontrando em condições clínicas de cirurgia, tendo sido iniciados cuidados paliativos. A paciente foi a óbito poucos dias após.

\section{Discussão}

O carcinoma tipo glassy cell de colo uterino é uma variante rara de carcinoma adenoescamoso pouco diferenciado. Alguns estudos têm observado uma associação com a gravidez. ${ }^{3}$

O exame de Papanicolaou é a ferramenta mais utilizada para rastreamento populacional do câncer de colo uterino por ser simples, seguro e de baixo custo. ${ }^{5}$

Entidades raras no exame de Papanicolaou são desafios na prática diária de citologia. Apesar de apresentar um quadro citológico que pode ser altamente sugestivo do diagnóstico em casos típicos, ${ }^{6}$ achados ultraestruturais de carcinoma do tipo glassy cell mostram evidências de diferenciação tanto escamosa quanto glandular ${ }^{4} \mathrm{e}$ essas características citológicas únicas podem levar a diagnósticos incorretos. A razão para essa baixa precisão diagnóstica pela citologia pode ser ocasionada também pela baixa frequência deste tumor.?

A presença de grande nucléolo é característica e pode ser confundida com inclusões de herpes vírus ou células de Reed-Stenberg da doença de Hodgkin. Também podem ser vistas vacuolização citoplasmática e células multinucleadas. ${ }^{3}$

Gray e colaboradores 2002, ${ }^{8}$ analisando 22 laudos de conização com diagnóstico de carcinoma tipo glassy cell encontraram apenas $28 \%$ com exame de Papanicolaou alterado em citologia prévia à conização.

A principal característica anatomopatológica do câncer do tipo glassy cell é a quantidade moderada de citoplasma granular pálido com aspecto de vidro moído, núcleos localizados centralmente com nucléolo proeminente, membranas celulares distintas e proeminente infiltração de eosinófilos no estroma. ${ }^{1}$

Receptores de estrogênio e progesterona foram encontrados em tumores do tipo glassy cell, sugerindo que este tumor pode ser responsivo a esses hormônios. ${ }^{9}$

Kato e colaboradores ${ }^{4}$ sugerem forte associação do tumor tipo glassy cell com o HPV 18, que poderia induzir a aparência "vítrea" do citoplasma possivelmente por induzir a diferenciação escamosa e glandular bifásica.

Alguns trabalhos questionam a agressividade do tumor. Hopkins e colaboradores, analisando 21 casos de glassy cell, não encontraram diferenças na sobrevida em comparação a outros tipos de adenocarcinoma. ${ }^{10}$

Gray e colaboradores ${ }^{8}$ observaram que o câncer tipo glassy cell parece ter melhor prognóstico quando diagnosticado em estádio I, com taxa de $85 \%$ de sobrevida global, concluindo que os fatores que levam a um pior prognóstico são invasão do espaço linfovascular, invasão estromal profunda e tumor maior do que $3 \mathrm{~cm}$.

Ferrnadina e colaboradores, 2008, ${ }^{11}$ relataram um caso de carcinoma cervical tipo glassy cell em estágio IB1 tratado por conização e linfadenctomia pélvica laparoscópica, com seguimento de 38 meses sem evidência de recorrência.

Guitarte e colaboradores, 2014, ${ }^{12}$ em metanálise recente, verificaram 292 casos em estádios I e II e concluíram tratar-se de um tumor de mulheres jovens com prognóstico pior quando comparado ao tipo escamoso.

A extensão da doença, no momento do diagnóstico, é um importante fator prognóstico e o estadiamento cirúrgico é frequentemente maior do que o clínico. Os cânceres tipo glassy cell são geralmente diagnosticados 
Leila C. Soares, Marco A. P. Oliveira. • Carcinoma de colo uterino tipo glassy cell

em um estágio avançado e demonstram tendência a desenvolver metástases pélvicas e extrapélvicas. A recidiva local geralmente ocorre no ápice vaginal e a disseminação pélvica ocorre para paramétrio, ovários e linfonodos paraórticos. ${ }^{2}$

Devido à raridade da doença e à falta de estudos prospectivos, o manejo da doença não está especificamente definido.12 Em estágios iniciais, o câncer tipo glassy cell de colo uterino pode ser tratado por histerectomia com linfadenectomia pélvica associada ou não à radioquimioterapia adjuvante. Em estágios avançados a radioquimioterapia neoadjuvante ou quimioterapia devem ser utilizadas com o objetivo de tornar a doença operável. ${ }^{13}$ Tanto a radiação quanto a cirurgia raramente são curativas para pacientes com doença avançada. ${ }^{14}$

$\mathrm{O}$ atraso no diagnóstico dessa paciente se deveu provavelmente ao fato de o exame de Papanicolaou ser normal e a lesão endofítica. É possível que pacientes com lesões exofíticas tendam a ser diagnosticadas e tratadas mais precocemente em comparação às com tumores de crescimento endofítico.

\section{Referências}

1. Takahashi Y, Sasaki H, Mogami H, et al. Adjuvant combined paclitaxel and carboplatin chemotherapy for glassy cell carcinoma of theuterine cervix: report of three cases with clinicopathological analysis. J Obstet Gynaecol Res. 2011;37(12):1860-3.

2. Nasu K, Takai N, Narahara H. Multimodal treatment for glassy cell carcinoma of the uterine cervix. J Obstet Gynaecol Res 2009;35:584-587.

3. Khalbuss WE, Michelow P, Benedict C, et al. Cytomorpholo- gy of unusual infectious entities in the Pap test. Cytojournal 2012;9:15.

4. Kato N, Katayama Y, Kaimori M, et al. Glassy cell carcinoma of the uterine cervix: histochemical, immunohistochemical, and molecular genetic observations. Int J Gynecol Pathol. 2002;21:134-40.

5. Gullo CE, Dami ALT, Barbosa AP, et al. Results of a control quality strategy in cervical cytology. Einstein. 2012;10:86-91.

6. Reis-Filho JS, Fillus Neto J, Schonemann E, et al. Glassy cell carcinoma of the uterine cervix. Report of a case with cytohistologic and immunohistochemical study. Acta Cytol 2001;45:407-10.

7. Kuroda H, Toyozumi Y, Masuda T, et al. Glassy cell carcinoma of the cervix: cytologic features and expression of estrogen receptor, progesterone receptor and Her2/neu protein. Acta Cytol. 2006;50:418-22.

8. Gray HJ, Garcia R, Tamimi HK, et al. Glassy cell carcinoma of the cervix revisited. Gynecol Oncol 2002;85:274-277.

9. Chung JH, Koh JS, Lee SS, et al. Glassy cell carcinoma of the uterine cervix. Cytologic features and expression of estrogen and progesterone receptors. Acta Cytol. 2000;44:551-6.

10. Hopkins MP, Morley GW. Glassy cell carcinoma of the uterine cervix. Am J Obstet Gynecol 2004;190:67-70.

11. Ferrandina G, Salutari V, Petrillo M, et al. Conservatively treated glassy cell carcinoma of the cervix. World J Surg Oncol. 2008;28:6:92.

12. Guitarte C, Alagkiozidis I, Mize B, et al. Glassy cell carcinoma of the cervix: A systematic review and meta-analysis. Gynecol Oncol. 2014;133:186-91.

13. Zolciak-Siwinska A, Jonska-Gmyrek J. Glassy cell carcinoma of the cervix: a literature review. Eur J Obstet Gynecol Reprod Biol. 2014;179:232-5.

14. Ukita $\mathrm{Y}$, Tsubamoto $\mathrm{H}$, Kato $\mathrm{T}$, et al. A case of primary metastatic glassy cell carcinoma of the uterine cervix that responded to combined docetaxel and carboplatin. Gynecol Oncol Case Rep. 2013;6:19-21. 